\title{
Establishment of patient-derived non-small cell lung cancer xenograft models with genetic aberrations within EGFR, KRAS and FGFR1: useful tools for preclinical studies of targeted therapies
}

Xu-chao Zhang ${ }^{1 \dagger}$, Jingchuan Zhang ${ }^{2 \dagger}$, Ming Li ${ }^{2}$, Xiao-sui Huang ${ }^{1}$, Xue-ning Yang ${ }^{1}$, Wen-zhao Zhong ${ }^{1}$, Liang Xie ${ }^{2}$,

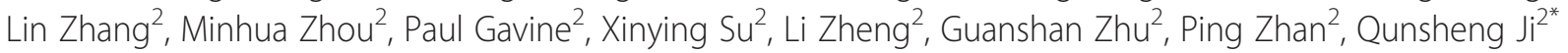
and Yi-long $\mathrm{Wu}^{1 *}$

\begin{abstract}
Background: Patient-derived tumor xenograft models have been established and increasingly used for preclinical studies of targeted therapies in recent years. However, patient-derived non-small cell lung cancer (NSCLC) xenograft mouse models are relatively few in number and are limited in their degree of genetic characterization and validation. In this study, we aimed to establish a variety of patient-derived NSCLC models and characterize these for common genetic aberrations to provide more informative models for preclinical drug efficacy testing.

Methods: NSCLC tissues from thirty-one patients were collected and implanted into immunodeficient mice. Established xenograft models were characterized for common genetic aberrations, including detection of gene mutations within EGFR and KRAS, and genetic amplification of FGFR1 and CMET. Finally, gefitinib anti-tumor efficacy was tested in these patient-derived NSCLC xenograft models.

Results: Ten passable patient-derived NSCLC xenograft models were established by implantation of NSCLC specimens of thirty-one patients into immunodeficient mice. Genetic aberrations were detected in six of the models, including one model with an EGFR activating mutation (Exon19 Del), one model with KRAS mutation, one model with both KRAS mutation and CMET gene amplification, and three models with FGFR1 amplification. Anti-tumor efficacy studies using gefitinib demonstrated that the EGFR activating mutation model had superior sensitivity and that the KRAS mutation models were resistant to gefitinib. The range of gefitinib responses in the patient-derived NSCLC xenograft models were consistent with the results reported from clinical trials. Furthermore, we observed that patient-derived NSCLC models with FGFR1 gene amplification were insensitive to gefitinib treatment. (Continued on next page)
\end{abstract}

\footnotetext{
*Correspondence: qunsheng.ji@astrazeneca.com; syylwu@live.cn

${ }^{\dagger}$ Equal contributors

${ }^{2}$ Innovation Center China, AstraZeneca Global R\&D, Zhangjiang Hi-Tech Park

Shanghai 201203, PR China

${ }^{1}$ Medical Research Center of Guangdong General Hospital \& Guangdong

Academy of Medical Sciences, Guangdong Lung Cancer Institute,

Guangzhou 510080, PR China

Full list of author information is available at the end of the article
} 
(Continued from previous page)

Conclusions: Ten patient-derived NSCLC xenograft models were established containing a variety of genetic aberrations including EGFR activating mutation, KRAS mutation, and FGFR1 and CMET amplification. Gefitinib anti-tumor efficacy in these patient-derived NSCLC xenografts containing EGFR and KRAS mutation was consistent with the reported results from previous clinical trials. Thus, data from our panel of patient-derived NSCLC xenograft models confirms the utility of these models in furthering our understanding of this disease and aiding the development of personalized therapies for NSCLC patients.

Keywords: NSCLC, Patient-derived NSCLC xenograft, EGFR/KRAS mutations, FGFR1 amplification

\section{Introduction}

Lung cancer is the leading cause of cancer-related mortality worldwide [1] and non-small cell lung cancer (NSCLC) accounts for over $80 \%$ of lung cancer deaths [2]. In addition to the traditional lung cancer treatments of surgery, radiation and chemotherapy, molecularly targeted drugs such as EGFR tyrosine kinase inhibitors (gefitinib and erlotinib) [3], and anaplastic lymphoma kinase (ALK) tyrosine kinase inhibitors (crizotinib) [4] have recently emerged as viable therapeutic options.

Preclinical evaluation of targeted therapies relies heavily on the use of animal tumor models [5,6], and the transplantation of standard tumor cell lines into mice to generate xenografts is common practice in preclinical drug discovery $[7,8]$. Unfortunately, following prolonged in vitro artificial culturing, these transplanted tumor cells often no longer maintain the original molecular characteristics and heterogeneity of the patient tumor $[9,10]$. One of the most profound issues with using standard xenograft models is their poor predictive power for the translation of preclinical efficacy into clinical outcome [11,12].

To overcome these disadvantages and build upon the industry's repertoire of standard xenograft tumor models, patient-derived xenograft mouse models have been successfully established by implanting fresh patient tumor fragments into immunodeficient mice, subcutaneously or orthotopically, and used to evaluate targeted therapeutic drugs in recent decades [5,12-14].

To date, a variety of tumor models representing key disease segments have been established using fresh patient tumor tissues, including colorectal cancer (CRC) [15], pancreatic cancer [16], lung cancer [17], gastric cancer [18], esophageal cancer [19], hepatocellular carcinoma (HCC) [20] and others [13]. Recent evidence suggests that patient-derived xenograft mouse models can maintain certain pathological and molecular features of the original disease and patient tumor [20]. Compared to standard cell line-derived xenograft models, the greatest advantage of patient-derived xenograft models is their ability to better predict clinical tumor response [6]. Notably, Fiebig et al. described a high correlation $(90 \sim 96 \%)$ between antitumor efficacy generated in patient-derived xenograft models and clinical response in patients. In many respects, patient-derived tumor xenograft models are increasingly being considered as more relevant models since the patient's tumor grows as a solid entity, develops a functional stroma and vasculature, and displays central necrosis and reflects tumor differentiation [6]. In a recent comprehensive review, the many advantages of patient-derived tumor xenograft models were summarized thus: 1) an accurate reflection of the complexity and heterogeneity of human tumors, 2) maintenance of the molecular, genetic and histological heterogeneity typical of the original tumors through serial passaging in mice, 3) provision of an excellent in vivo preclinical platform to study cancer stem biology and stromal-tumor interactions, 4) presentation of an information-rich preclinical resource for the analysis of drug activity, including novel-novel drug combinations, as well as predictive biomarker discovery, and finally 5) provision of a more-relevant system to test clinically directed hypotheses [21]. Thus, these clinically-relevant animal tumor models are anticipated to increase the success of identifying new active antitumor agents for targeted therapy. Furthermore, the increased genetic diversity within these patient-derived xenograft models also provides opportunities to further develop personalized approaches for the treatment of NSCLC patients.

To preclinically model the major disease segments within lung cancer, patient-derived NSCLC xenograft mouse models have been established, and further characterization has shown that these models accurately represent the patient's genetic diversity and tumor morphology $[17,22]$. To our knowledge however, targeted therapeutic drugs such as the EGFR tyrosine kinase inhibitor gefitinib, have not been tested within a variety of patientderived NSCLC xenograft models with differing genetic aberrations and compared with clinical trial outcome data.

In this study, we established ten passable patient-derived NSCLC xenograft models from thirty-one implanted patient NSCLC samples. These contained a variety of genetic aberrations including: EGFR and KRAS gene mutations and genetic amplification of $c M E T$ and FGFR1. Within these models, gefitinib antitumor activity was generally poor, and tumor regression was only observed in a model containing an EGFR exon 19 deletion - consistent with 
previous preclinical studies and supportive of the current patient selection criteria for EGFR-targeted therapies, such as gefitinib and erlotinib. These clinically relevant NSCLC xenograft models thus provide useful tools for the evaluation and development of molecularly targeted therapeutic drugs for the treatment of NSCLC patients.

\section{Materials and methods \\ Patient samples}

Thirty-one NSCLC patient specimens were obtained at initial surgery from primary diagnosed, early-stage NSCLC patients from Guangdong General Hospital. Written informed consent was obtained from each patient and the study was approved by the hospital ethics committee. Tumor pathology was diagnosed by hospital pathologist. Harvested fresh NSCLC specimens were separated into three parts: the first part was cut into fragments of around $15 \mathrm{~mm}^{3}$ under sterile conditions and put into frozen medium, containing 90\% fetal bovine serum (FBS) (Gibco, Cat\#10099-141, Australia) and 10\% dimethyl sulfoxide (DMSO) (Sigma, Cat\#D2650, USA), and then stored in liquid nitrogen for later implantation; the second part of the specimen was snap frozen immediately in liquid nitrogen for DNA/RNA extraction and the third part of the specimen was fixed in formalin (SCRC, Cat\#10010018, China) and embedded into paraffin (Thermo Scientific, Cat\#6774060, USA) for pathological assessment and model characterization.

Establishment of patient-derived NSCLC xenograft models 8-10-week-old female severe combined immunodeficient (SCID) and nude $(n u / n u)$ mice (Vital River, Beijing, China) were used in this study. All animal studies were performed in accordance with the guidelines approved by the Institutional Animal Care and Use Committee (IACUC). The patient-derived NSCLC xenograft mouse models were established using surgically removed tissues from NSCLC patients as described previously [5] and modified. Frozen NSCLC tissues in medium with $90 \%$ FBS were thawed at $37^{\circ} \mathrm{C}$ and implanted into SCID mice subcutaneously via Trocar needle. The tumor-implanted mice were observed daily for 90 days. Tumors were measured once a week by caliper to determine subcutaneous growth rate. Xenografted NSCLC tumors $\left(\sim 500 \mathrm{~mm}^{3}\right)$ in SCID mice were further implanted into nude mice for further generations of these models. After three consecutive mouse-to-mouse passages, the xenograft models became stable and were then submitted for model characterization, including histopathology confirmation, gene mutation detection for EGFR and KRAS, and gene amplification for FGFR1 and $c M E T$ by detection of fluorescence in situ hybridization (FISH) assay. The tumor specimens in each passage of tumor-bearing mice were harvested and divided into three parts for the following purposes.
The first part was implanted into nude mice for generation of the second xenograft passage. The second part was used for DNA/RNA extraction by snap freezing in liquid nitrogen. The third part was fixed in $10 \%$ formalin buffer for 24 hours and embedded in paraffin (FFPE) for gene amplification by FISH analysis. Larger amounts of fresh tumor fragments at passage 3-5 were frozen in the standard cell freezing medium and stored in liquid nitrogen for model banking. The patient-derived NSCLC xenograft mouse models were maintained in nude mice and used for anti-tumor efficacy studies, prior to reaching passage ten. Hematoxylin and eosin (H\&E) staining was performed to confirm the histopathology of xenografts.

\section{Mutation detection}

NSCLC patient tissues and xenograft tissues from the patient-derived NSCLC xenograft mouse models were pathologically reviewed to ensure that tumor cell content was more than $80 \%$ and that no significant tumor necrosis had occurred before extraction of DNA. Genomic DNA was extracted from each tissue sample using Puregene Cell and Tissue Kit (QIAGEN, Cat\#158388, Germany). The quantity and purity of DNA samples were measured using Nanodrop ND-1000 UV/VIS Spectrophotometer (Thermo Scientific, USA). DNA fragment integrity was confirmed by electrophoresis using 1\% agarose gel. The concentration of DNA samples were normalized to $20 \mathrm{ng} / \mu \mathrm{L}$ and stored at $-20^{\circ} \mathrm{C}$ until use. 'Hot spot' mutations in EGFR (exons 18, $19,20,21$ ) and $K R A S$ (exons 2 and 3) were screened by amplification refractory mutation system (ARMS) and mutant-enriched liquid chip polymerase chain reaction (PCR) method. The former method and detection was supported by Amoy diagnostics Co. Ltd, Fujian, PR China, the latter method was performed at SurExam Bio-Tech Co. Ltd., Guangzhou Technology Innovation Base, Science City, Guangzhou, PR China.

FGFR1 and MET gene amplification analysis by FISH assay The FGFR1 FISH probe was generated internally (AstraZeneca) by directly labeling bacteria artificial chromosome (BAC) (CTD-2288 L6, Invitrogen, USA) DNA with Spectrum Red (Vysis, Cat\# 30-803400, USA). The CEP8- Spectrum Green probe (Vysis, Cat\#32-132008, USA) for the centromeric region of chromosome (CEP) 8 was used as internal control. For MET FISH probe generation, BAC (CTD-2270 N20, Invitrogen, USA) DNA was used and CEP7-Spectrum Green probe (Vysis, Cat\#06 J37007, USA) as internal control.

FISH assays were performed on 4 micron dewaxed and dehydrated FFPE sections. The SpotLight Tissue pretreatment Kit (Invitrogen, Cat\#00-8401, USA) was used for pretreatment (boiled in reagent 1 for $\sim 15$ minutes then coated with reagent 2 for $\sim 10$ minutes, minor time adjustments were made for individual samples). Sections and 
probes were codenaturated at $80^{\circ} \mathrm{C}$ for 5 minutes and then hybridized at $37^{\circ} \mathrm{C}$ for 48 hours. After a quick post wash off process $\left(0.3 \% \mathrm{NP} 40 / 1 \mathrm{xSSC}\right.$ at $75.5^{\circ} \mathrm{C}$ for 5 minutes, twice in $2 \times$ saline sodium citrate [SSC] at room temperature for 2 minutes), sections were finally mounted with $0.3 \mu \mathrm{g} / \mathrm{ml}$ 4;6-diamidino-2-phenylindole (DAPI) (Vector, Cat\# H1200 , USA), and stored at $4^{\circ} \mathrm{C}$ avoiding light for at least 30 minutes prior to scoring.

Target gene and CEP signals were observed using fluorescence microscope equipped with the appropriate filters allowing visualization of the intense red target gene signals, the intense green chromosome centromere signals, and the blue counterstained nuclei. Enumeration of the FGFR1 or MET gene and chromosome 8 or 7 was conducted by microscopic examination of 50 tumor nuclei, which yielded a ratio of FGFR1 to CEP8 or MET/CEP7. Tumors with ratio $\geq 2$ or presence of $\geq 10 \%$ gene cluster were defined as amplification.

\section{Anti-tumor activity}

Tumor growth curves in all patient-derived NSCLC xenograft models were generated by kinetic measurement of tumor volumes subcutaneously. For therapeutic experiments, the tumor volume range of 150 to $250 \mathrm{~mm}^{3}$ in tumor-bearing nude mice were sorted randomly $(6 \sim 8$ animals per group) and assigned to vehicle control or gefitinib treatment groups by oral dosing at $100 \mathrm{mg} / \mathrm{kg}$ (AstraZeneca, AZ10027436, England). Subcutaneous tumor volumes in nude mice and mouse body weights were measured twice a week. Tumor volumes were calculated by measuring two perpendicular diameters with calipers. Tumor volumes (TV) calculated by the formula: TV = (length $\times$ width $\left.^{2}\right) / 2$. Percentage of tumor growth inhibition (\%TGI) was calculated as the formula: $\{1-$ [change of tumor volume in treatment group/change of tumor volume in control group] $\} \times 100$ and was used for the evaluation of anti-tumor efficacy.

\section{Statistical analysis}

To find out clinical parameters that contribute to the success of model establishment, logistic regression was used to assess the association of success rate of model establishment with clinic-pathological parameters. A patient tissue that can be successfully turned into a xenograft model is defined as 1 and 0 otherwise. $P$ values from univariate models were computed from loglikelihood ratio test. Factors that show significant results from univariate analysis were considered in multivariate analysis to adjust for imbalance of covariates, including gender, histological type and smoking status. The data analysis was performed using $\mathrm{R}$ version 2.11 .0 on Unix. To evaluate the statistic significance in anti-tumor efficacy study, Student's t-test was used to compare TGI in treatment group to the control group. Statistical tests were two sided, with $\mathrm{P}<0.05$ considered significant.

\section{Results}

\section{Establishment of patient-derived NSCLC xenograft mouse models.}

Thirty-one patient NSCLC specimens were harvested and implanted subcutaneously into SCID mice. Ten patient-derived NSCLC xenograft models from the thirty-one implantations were established in consecutive passages in nude mice (Table 1). NSCLC patient clinical information is also listed in Table 1 . None of the patients received any therapies prior to surgery. The original patient NSCLC tissues were implanted into SCID mice subcutaneously and then growing xenograft tissues were implanted into nude mice starting from the second generation of models. The model success rate was $45 \%$ $(14 / 31)$ in the first generation of SCID mice, and then $32 \%(10 / 31)$ in the second and subsequent generations. After the second generation, patient-derived NSCLC xenograft models became stable without further changes in model survival and tumor take-on rates. All ten established patient-derived NSCLC xenograft models showed kinetic growth curves in passage 3 (Figure 1). Examination of autopsies in NSCLC-bearing mice from these xenograft mouse models at $2 \sim 3$ months post-implantation revealed no evidence of metastases in brain, lung, liver or kidney. The xenograft tissues were analyzed by H\&E staining for pathology assessment. The patient-derived NSCLC xenograft tissues exhibited similar morphology to that of the patient tissues from which the primary models were derived (data not shown). Following this, established patient NSCLC xenografts were submitted for model characterization and further validation by targeted therapy.

Results of the correlation analysis between model establishment success rate and patient clinical parameters are listed in Table 2. Multivariate analysis showed that tumor histological subtype was the only parameter which had significant impact on the success rate of model establishment. Squamous cell carcinoma (SCC) was much more prone to be tumorigenic in nude mice compared to adenocarcinoma $(\mathrm{AC})$. Other factors, including sex, smoking status, pathologic grade and mutation, did not correlate with model success rate; although univariate analysis showed that sex and smoking status have a significant impact when these parameters are considered alone.

\section{Genetic aberrations within patient-derived NSCLC xenograft models}

Mutation of EGFR, KRAS and gene amplification of FGFR1 and $c M E T$ were screened for in all 31 patient samples and ten established xenograft samples. One model with an EGFR activating mutation (Exon19Del) and two models with KRAS mutations (G12S and Q61H) were 
Table 1 Information of patients and corresponding patient-derived xenograft mouse models

\begin{tabular}{|c|c|c|c|c|c|c|c|c|c|}
\hline$\#$ & Model & Gender & Smoking status & EGFR/Kras mutation & Age & Pathology & Stage & TNM stage & Engrafted model \\
\hline 1 & L004 & M & Y & WT & 61 & $A C$ & $\| \mathrm{A}$ & $\mathrm{T} 2 \mathrm{~N} 2 \mathrm{MO}$ & Yes \\
\hline 2 & L023 & M & Y & Kras:G12S & 55 & SCC & $\| \mathrm{A}$ & T3N2M0 & Yes \\
\hline 3 & L030 & M & Y & Q61H & 64 & SCC & IV & T2N0M1 & Yes \\
\hline 4 & L101 & M & Y & WT & 63 & $A C$ & IA & T1NOMO & No \\
\hline 5 & L102 & $\mathrm{F}$ & $\mathrm{N}$ & WT & 53 & $A C$ & IA & T1NOMO & No \\
\hline 6 & L103 & M & $\mathrm{N}$ & $\mathrm{n} / \mathrm{a}$ & 45 & SCC & $\| \mathrm{A}$ & T3NOMO & No \\
\hline 7 & L104 & M & $N$ & WT & 71 & SCC & $\| B$ & T2N1M0 & Yes \\
\hline 8 & L105 & M & $N$ & WT & 76 & $A C$ & $\mathrm{IB}$ & T2NOMO & No \\
\hline 9 & L106 & $\mathrm{F}$ & $N$ & Exon19Del & 67 & $A C$ & $\| B$ & T2N1M0 & No \\
\hline 10 & L107 & M & Y & WT & 76 & SCC & IB & T2NOMO & No \\
\hline 11 & L108 & $\mathrm{F}$ & $\mathrm{N}$ & L858R & 71 & $A C$ & $\| B$ & T2N1M0 & No \\
\hline 12 & L110 & M & Y & WT & 66 & SCC & $\mathrm{IB}$ & T2NOMO & Yes \\
\hline 13 & L111 & M & $\mathrm{N}$ & L858R & 72 & $A C$ & IA & T1NOMO & No \\
\hline 14 & L113 & M & Y & WT & 73 & SCC & $\mathrm{IB}$ & CT2NOMO & No \\
\hline 15 & L115 & M & $\mathrm{n} / \mathrm{a}$ & Exon19Del & 55 & $\mathrm{AC} / \mathrm{SCC}$ & $\| \mathrm{A}$ & T2N2M0 & Yes \\
\hline 16 & L116 & M & $N$ & WT & 57 & SCC & $\| \mathrm{II}$ & $\mathrm{ST} 2 \mathrm{~N} 2 \mathrm{MO}$ & No \\
\hline 17 & L117 & M & $N$ & WT & 66 & $A C$ & $\| B$ & ST2N1M0 & No \\
\hline 18 & L118 & M & Y & L858R & 31 & $A C$ & IV & T1N0M1 & No \\
\hline 19 & L119 & M & Y & WT & 48 & $A C$ & $\mathrm{IA}$ & ST1NOM0 & No \\
\hline 20 & L121 & M & Y & WT & 69 & SCC & IV & T2NOM1 & Yes \\
\hline 21 & L123 & M & Y & WT & 50 & SCC & IB & T2NOMO & Yes \\
\hline 22 & L124 & $\mathrm{F}$ & $N$ & L858R & 50 & $A C$ & $\| \mathrm{A}$ & T2N2Mx & No \\
\hline 23 & L125 & $\mathrm{F}$ & $\mathrm{N}$ & WT & 47 & $A C$ & IIIA & $\mathrm{T} 2 \mathrm{~N} 2 \mathrm{MO}$ & No \\
\hline 24 & L126 & M & $N$ & WT & 59 & $A C$ & IB & T2NOMO & No \\
\hline 25 & L127 & $\mathrm{F}$ & $N$ & L858R & 66 & $A C$ & IB & T2NOMO & No \\
\hline 26 & L128 & M & Y & WT & 61 & SCC & IIIA & T2N2M0 & No \\
\hline 27 & L130 & M & $N$ & $\mathrm{n} / \mathrm{a}$ & 66 & SCC & IB & T2NOMO & No \\
\hline 28 & L131 & $\mathrm{F}$ & $N$ & Kras:G12V & 60 & $A C$ & IV & NOM1 & No \\
\hline 29 & L132 & M & Y & WT & 69 & $A C$ & $\| \mathrm{A}$ & ST3N1M0 & No \\
\hline 30 & L133 & M & $N$ & WT & 61 & SCC & $\| B$ & T2N1M0 & Yes \\
\hline 31 & L140 & M & Y & WT & 58 & SCC & IIIA & $\mathrm{T} 2 \mathrm{~N} 2 \mathrm{M} 0$ & Yes \\
\hline
\end{tabular}

identified in the ten patient-derived NSCLC models and their corresponding patient NSCLC tissues (Table 3). Furthermore, gene amplification of FGFR1 was detected in additional three models and $c M E T$ in one model (KRAS mutant background). Again, these genetic aberrations were identified in both patient-derived NSCLC models and their corresponding patient NSCLC tissues (Table 3 and Figure 2), with the exception of one model (L123) which lacked sufficient patient LC tissue for analysis.

\section{Gefitinib antitumor activity}

To validate and confirm whether these patient-derived NSCLC xenograft models showed similar responses to gefitinib treatment as compared to that reported in clinical trials, eight of the ten established xenograft models were treated with the EGFR tyrosine kinase inhibitor gefitinib (Table 3 and Figure 3). Xenograft model L115 which harbored an EGFR activating mutation (Exon19Del), responded completely to gefitinib treatment (tumors regressed completely during the treatment period). Interestingly, these tumors remained almost indistinguishable for nearly 40 days following cessation of gefitinib dosing. Xenograft model L030, with a KRAS mutation and EGFR wild type gene, showed a minor response to gefitinib treatment (25\% tumor growth inhibition (TGI)). A further KRAS mutation model (L023) with $c M E T$ gene amplification had no response to gefitinib treatment. Not surprisingly, the patient-derived 


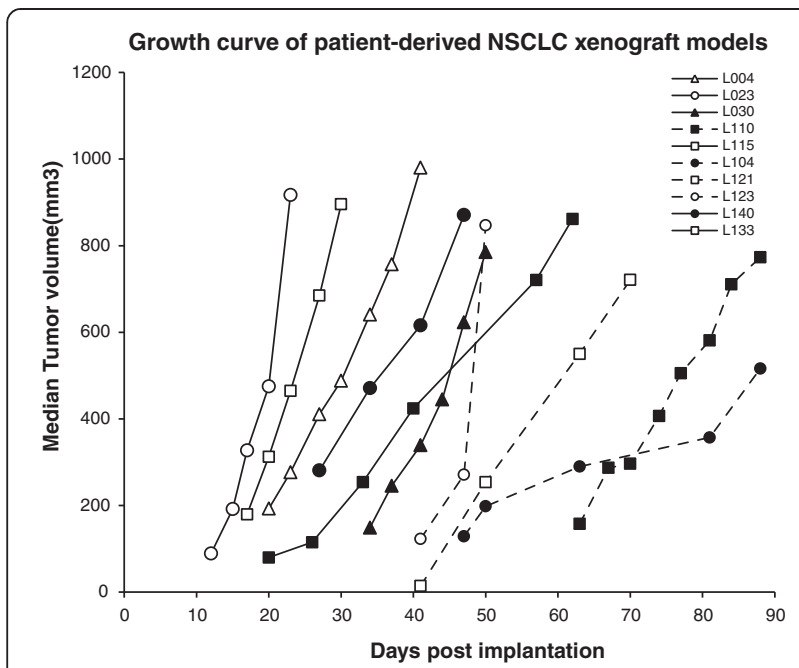

Figure 1 In vivo growth curves of patient-derived NSCLC xenograft models. Tumor growth curves of patient-derived NSCLC xenograft models. The models were established subcutaneously and tumor growth curves in passable and stable xenograft models were generated by tumor measurement between passage 3-5 (F3-5). Media of tumor volume was showed.

NSCLC xenograft models, L121 \& L123 with FGFR1 gene amplification were insensitive to gefitinib treatment (Table 3 and Figure 3), likely due to a tumor-dependence on FGFR pathway signaling [23,24]. Additional models, L104 and L004 with wild type EGFR and KRAS but without FGFR1 and $c M E T$ gene amplification showed moderate response to gefitinib, ranging from $46 \%$ to $113 \%$ TGI (Table 3 and Figure 3).

\section{Discussion}

As NSCLC remains one of the most lethal malignancies worldwide $[1,2,25]$, we urgently need to improve our understanding of the disease and assess whether novel patientderived NSCLC xenograft models can more faithfully represent clinical disease and gauge response to targeted therapies. We established ten patient-derived NSCLC xenograft mouse models derived from frozen patient tissues and characterized these models for relevant gene mutations and amplifications. In previous reports, patient-derived NSCLC xenograft models were established by implanting fresh patient tumor tissues with success rates ranging from $25 \sim 40 \%[5,22]$. To establish whether frozen tumor tissues could also be used to generate patient-derived xenograft models, we directly implanted frozen patient NSCLC tissues into mice. Using this method, we achieved a success rate of $32 \%$ (10/31 implantation), within a similar range to that achieved using fresh tissue implantation. An obvious benefit of this method however, is that patient tumor tissues can be collected at multiple medical centers, frozen on site and shipped to a central animal facility for model establishment, characterization and testing.
Here, as with others $[5,13]$, we have shown that implantation of human NSCLC tissue (in our case frozen tissue) can be viable and lead to successful model development in SCID mice. In our experience however, nude mice models are preferable in drug discovery due to their superior tolerability of drug agents and hence, we transferred our established patient-derived NSCLC models from SCID to nude mice. Our studies demonstrated that $71 \%(10 / 14)$ of our xenograft models in SCID mice could be successfully transferred to nude mice starting from the 2nd generation. After the third generation, in our study the models became more stable in terms of both tumor take-on and success rates.

To date, the major factors which affect the success rates of establishing patient-derived xenograft models in mice are still unclear. We suggest that tumor type may be one of the key factors. Clearly, SCC is easier to grow up in mice than $\mathrm{AC}$ [22], and higher success rates have been observed in establishing SCC patient-derived xenograft tumor models compared to all other types of patient-derived tumor [22]. Thomas John et al. have recently demonstrated that patient samples with EGFR gene mutations are difficult to grow up and passage in immunodeficient mice. Our data in this study also support this observation (Table 2). Clinical characteristics, such as patient clinical stage, pathological grade and gender showed no correlation with the success rates of the patient-derived NSCLC xenograft models. This is a similar observation to those of other investigators in this field $[5,14,26,27]$. However, patient tumors with late stage and higher tumor grade tended to be passaged further in mice [26]. On the other hand, univariate analysis showed that sex and smoking status both significantly affected the success rate of patient-derived xenograft model establishment, however multivariate analysis failed to show this correlation. This result implies that males and smokers are more prone to developing SCC, and consequently that female patients and non-smokers are more prone to developing AC. Furthermore, we observed that the quality of the tumor samples provided by surgeons was one of the most important factors for successful engraftment of patient-derived tumor xenograft models (unpublished ongoing studies).

One of the most important advantages in developing patient-derived NSCLC xenograft models is that the model can better represent the genetic diversity and molecular characteristics of the original NSCLC patient tumor [22]. With regard to the carryover of genetic mutations from patient NSCLC tissues to mouse xenograft tissues, data from our study showed that genotypes are consistent between the original patient tumor and the corresponding xenograft tissue in all ten models for EGFR and KRAS status. In addition to mutations, our data also demonstrated that these patient-derived 
Table 2 Relationship of model establishment rate and patients' clinical information

\begin{tabular}{|c|c|c|c|c|c|}
\hline Patient information & Patient \# & Derived model \# & Established rate (\%) & $P$ value (univariate) & $P$ value (multivariate) \\
\hline Sex & & & & 0.0115 & 0.1896 \\
\hline Male & 24 & 10 & 42 & & \\
\hline Female & 7 & 0 & 0 & & \\
\hline Histologic type & & & & 0.0015 & 0.0218 \\
\hline SCC & 15 & 9 & 60 & & \\
\hline$A C$ & 16 & 1 & 6 & & \\
\hline Pathologic stage & & & & 0.5017 & $\mathrm{n} / \mathrm{a}$ \\
\hline Stage I & 12 & 2 & 17 & & \\
\hline Stage II & 7 & 3 & 43 & & \\
\hline Stage III/IV & 11 & 4 & 36 & & \\
\hline Smoke status & & & & 0.0228 & 0.4631 \\
\hline Smoker & 14 & 7 & 50 & & \\
\hline Non-smoker & 16 & 2 & 12.5 & & \\
\hline Mutation & & & & 0.1031 & $\mathrm{n} / \mathrm{a}$ \\
\hline EGFR & 7 & 1 & 14 & & \\
\hline KRAS & 3 & 2 & 67 & & \\
\hline
\end{tabular}

NSCLC xenograft models carry gene amplifications in 4/10 models, including FGFR1 and $C M E T$, which are known anti-tumor drug targets [28-30]. Thus, these novel xenograft models represent useful tools for the preclinical study of emerging targeted therapies.

Although the work of Judde et al. demonstrated a gefitinib anti-tumor response in a patient-derived NSCLC model (58\% TGI) [31], genetic aberrations were not explored and characterized in detail across multiple models. In an effort to verify whether these novel models with different genetic aberrations exhibited a similar antitumor response to targeted therapy, we tested the efficacy of gefitinib in model L115, harboring an exon 19 deletion within EGFR. Gefitinib is an anti-EGFR agent shown to have clinical activity for the treatment of EGFR mutation positive NSCLC patients [32]. In clinical studies, gefitinib induces initial tumor regressions in lung cancer patients with EGFR activating mutations, including Exon19 Del, L858R mutation, and has no significant anti-tumor activity in lung cancer patients with KRAS mutation [32]. Our data confirmed a very consistent response profile in the patient-derived NSCLC models. Model L115 responded completely to gefitinib treatment over 20 days of dosing (tumor disappeared), and displayed only very slow regrowth

Table 3 Patient samples and corresponding patient-derived NSCLC xenograft model information

\begin{tabular}{|c|c|c|c|c|c|c|c|c|c|c|}
\hline \multirow[t]{3}{*}{ Model ID } & \multicolumn{5}{|c|}{ Patient NSCLC tissue implanted } & \multicolumn{5}{|c|}{ Patient derived LC xenograft models } \\
\hline & \multirow[t]{2}{*}{ Pathology } & \multicolumn{2}{|c|}{ Mutation detection } & \multicolumn{2}{|c|}{ Gene amplification } & \multicolumn{2}{|c|}{ Mutation detection } & \multicolumn{2}{|c|}{ Gene amplification } & \multirow{2}{*}{$\begin{array}{l}\% \mathrm{TGI} \\
\text { by Gefitinil }\end{array}$} \\
\hline & & $\overline{E G F R}$ & KRAS & FGFR1 & MET & $\overline{E G F R}$ & KRAS & FGFR1 & MET & \\
\hline L004 & $A C$ & WT & WT & None & None & WT & WT & None & None & 113 \\
\hline L023 & SCC & WT & G12S & None & AMP & WT & G12S & None & AMP & 0 \\
\hline L030 & SCC & WT & Q61H & None & None & WT & Q61H & None & None & 25 \\
\hline L104 & SCC & WT & WT & None & None & WT & WT & None & None & 46 \\
\hline L110 & SCC & WT & WT & None & None & WT & WT & None & None & 78 \\
\hline L115 & SCC & Exon19Del & WT & None & None & Exon19Del & WT & None & None & 199 \\
\hline L121 & SCC & WT & WT & AMP & None & WT & WT & AMP & None & 23 \\
\hline L123 & SCC & WT & WT & N/A & None & WT & WT & AMP & None & 47 \\
\hline L133 & SCC & WT & WT & AMP & None & WT & WT & AMP & None & N/A \\
\hline L140 & SCC & WT & WT & None & None & WT & WT & None & None & N/A \\
\hline
\end{tabular}




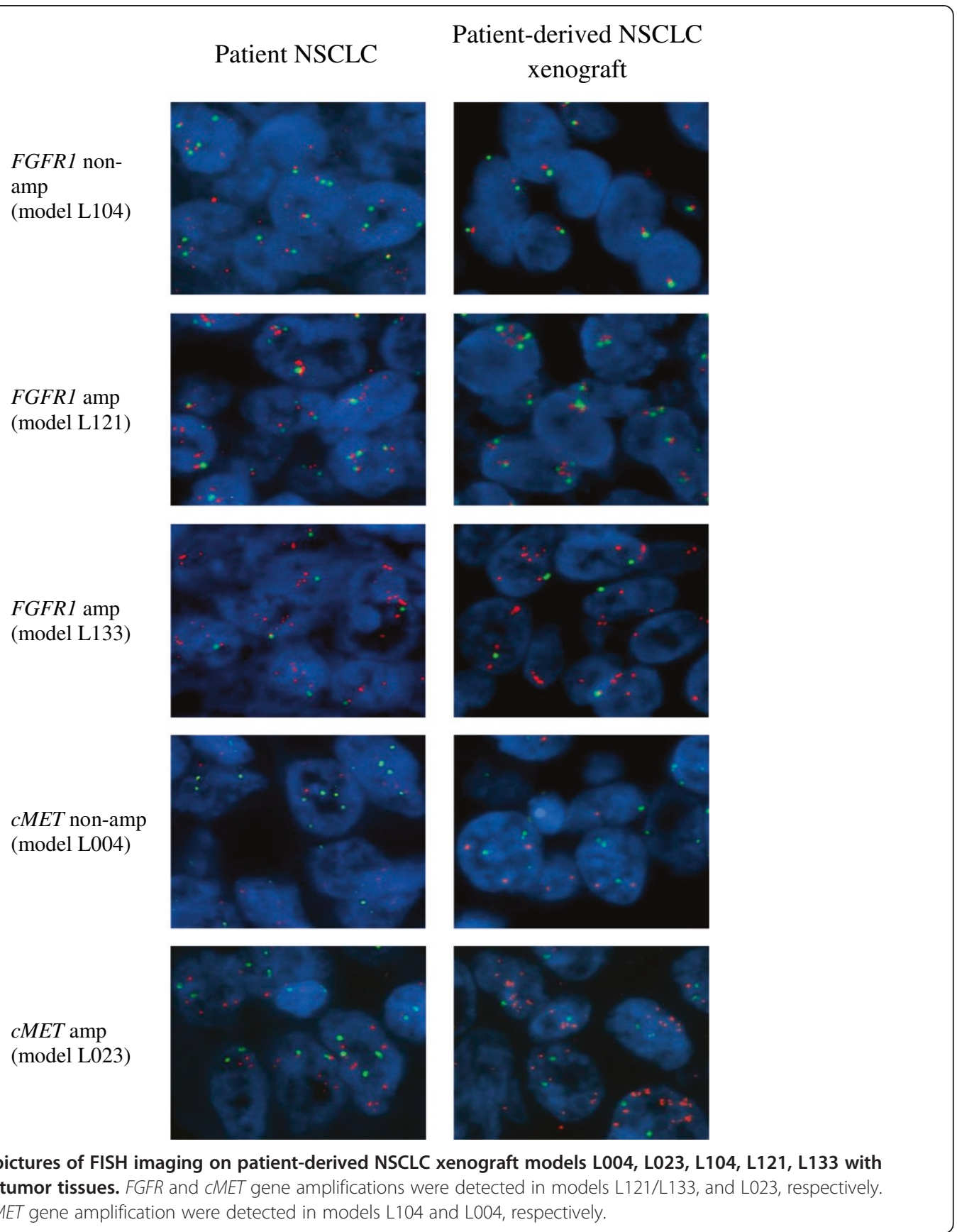

after 38 days post-dose cessation (Figure 3A). Two of the models with KRAS mutation were insensitive to gefitinib treatment. Interestingly, one KRAS mutation model, L030 showed little response to gefitinib (25\% TGI), but the other, L1023 (KRAS mutation concurrent with $c M E T$ gene amplification) showed no response at all (0\% TGI in L023 model).

FGFR1 represents a promising new target in lung cancer therapy [28]. Here, we tested two of three FGFR1 gene amplified models derived from NSCLC patients with gefitinib. Compared to the EGFR activating mutation model, these two FGFR1 gene amplified models, L121 and L123 were relatively insensitive to gefitinib treatment (TGI $=23 \%$, and $47 \%$, respectively). These models are likely 'oncogene addicted' to FGFR1 and indeed, potent tumor regressions have been previously observed in these 2 models using the selective small molecule inhibitor, AZD4547 [24]. A third FGFR1 amplified model, L133, failed to show a potent response to AZD4547 due to a lack of FGFR1 protein expression. Without question, 

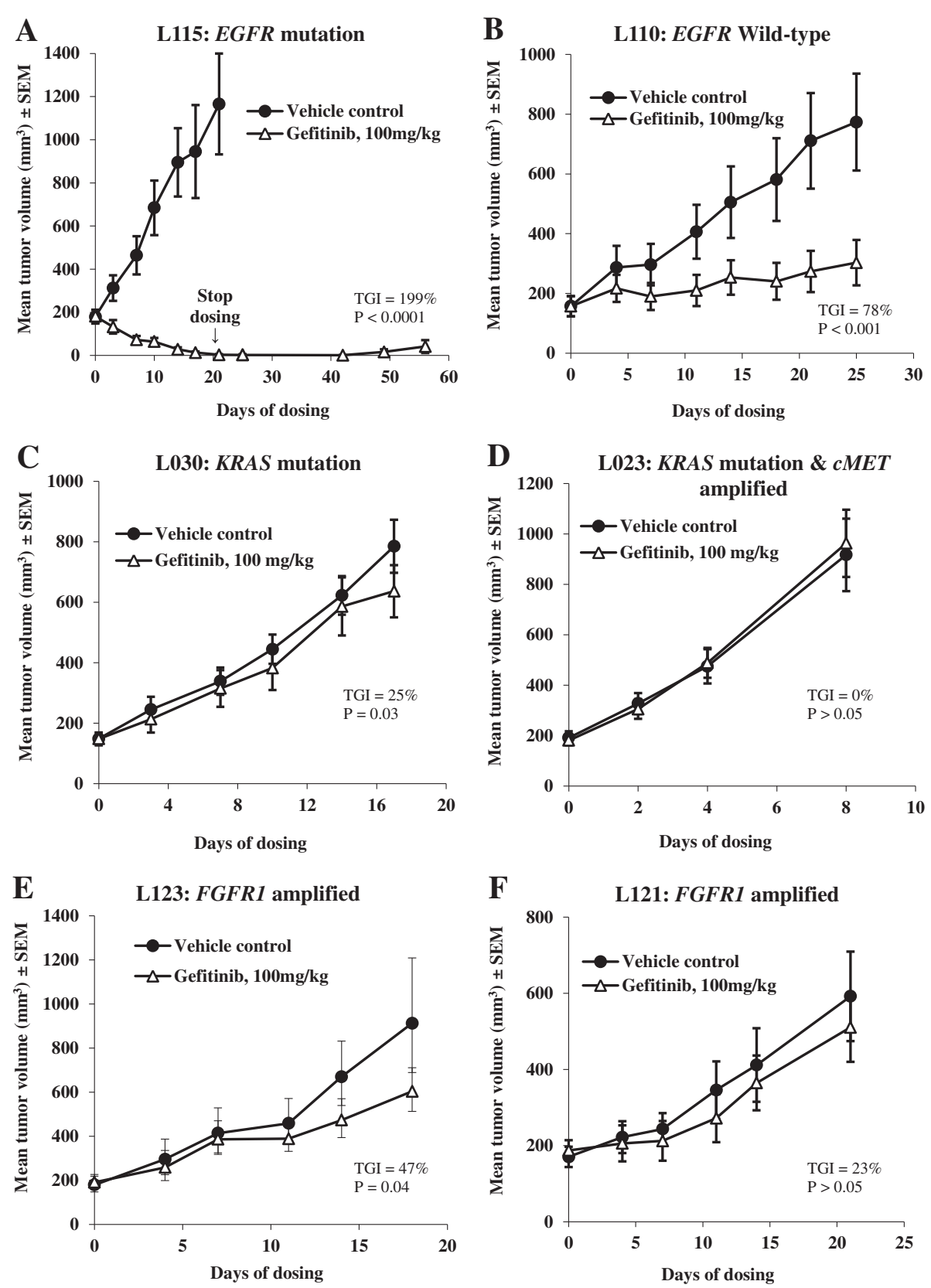

Figure 3 Efficacy study in patient-derived NSCLC xenograft models. Tumor-bearing nude mice were treated with either vehicle control or gefitinib at $100 \mathrm{mg} / \mathrm{kg}$ orally daily dosing for $1 \sim 3$ weeks based on tumor growth rates in different patient-derived NSCLC xenograft models when tumors reached $150 \sim 250 \mathrm{~mm}^{3}$ post implantation. Genetic aberrations within each of the models (A-F) are labeled in the graph title. Within the models, EGFR, KRAS, MET and FGFR1 are wild-type and non-amplified unless otherwise stated in the graph title.

these patient-derived NSCLC xenograft models harboring FGFR1 gene amplification have been extremely useful tools in testing the hypothesis that FGFR1 is a driving oncogene in NSCLC.

In summary, ten patient-derived NSCLC xenograft models were established harboring a variety of genetic aberrations including; EGFR activating and KRAS mutations, and FGFR1 and $c M E T$ gene amplification. Within those models with EGFR and KRAS mutation, the antitumor efficacy of the EGFR tyrosine kinase inhibitor, gefitinib, was consistent with published preclinical data [33] and clinical responses [34-36]. Finally, these patientderived NSCLC xenograft models represent useful tools to further understand this lethal disease and to enable development of personalized approaches for the treatment of NSCLC patients. 


\section{Competing interests}

The authors declare that they have no competing interests.

\section{Authors' contributions}

$X Z$ and $J Z$ participated in study design and coordination and drafted the manuscript. $X H, Z Y$ and $W Z$ collected and characterized the fresh patient tumor tissues. $M L, L X, L Z$ and $M Z$ performed the establishment of animal tumor models and efficacy study. GZ participated in the sequence alignment. LZ and XS completed immunochemistry and the FISH studies. PZ performed the statistical analysis. PG revised the manuscript. YW and QJ conceived of the study and participated in its design. All authors read and approved the final manuscript.

\section{Acknowledgements}

The authors thank Sunny Sun and Joan Fan for their excellent technical assistance on detection of mutations and gene amplification, Jie Zang for drafting figures.

\section{Author details}

${ }^{1}$ Medical Research Center of Guangdong General Hospital \& Guangdong Academy of Medical Sciences, Guangdong Lung Cancer Institute Guangzhou 510080, PR China. ${ }^{2}$ Innovation Center China, AstraZeneca Global R\&D, Zhangjiang Hi-Tech Park Shanghai 201203, PR China.

Received: 12 March 2013 Accepted: 8 July 2013

Published: 10 July 2013

\section{References}

1. Ramalingam SS, Owonikoko TK, Khuri FR: Lung cancer: New biological insights and recent therapeutic advances. CA Cancer J Clin 2011, 61:91-112.

2. Favaretto AG, Pasello G, Magro C: Second and third line treatment in advanced non-small cell lung cancer. Discov Med 2009, 8(43):204-209.

3. Maione P, Rossi A, Sacco PC, Bareschino MA, Schettino C, Gridelli C: Advances in chemotherapy in advanced non-small-cell lung cancer. Expert Opin Pharmacother 2010, 11(18):2997-3007.

4. Kwak EL, Bang YJ, Camidge DR, Shaw AT, Solomon B, Maki RG, Ou SH, Dezube BJ, Jänne PA, Costa DB, Varella-Garcia M, Kim WH, Lynch TJ, Fidias P, Stubbs H, Engelman JA, Sequist LV, Tan W, Gandhi L, Mino-Kenudson M, Wei GC, Shreeve SM, Ratain MJ, Settleman J, Christensen JG, Haber DA, Wilner K, Salgia R, Shapiro Gl, Clark JW, lafrate AJ: Anaplastic lymphoma kinase inhibition in non-small-cell lung cancer. N Engl J Med 2010, 363(18):1693-1703.

5. Fichtner I, Rolff J, Soong R, Hoffmann J, Hammer S, Sommer A, Becker M, Merk J: Establishment of patient-derived Non-small cell lung cancer xenografts as models for the identification of predictive biomarkers. Clin Cancer Res 2008, 14:6456-6468.

6. Fiebig HH, Dengler WA, Roth T: Human tumor xenografts: predictivity, characterization and discovery of new anticancer agents. Contrib Oncol. Basel Karger 1999, 54:29-50.

7. Troiani T, Schettino C, Martinelli E, Morgillo F, Tortora G, Ciardiello F: The use of xenograft models for the selection of cancer treatments with the EGFR as an example. Crit Rev Oncol Hematol 2008, 65:200-211.

8. Sausville A, Bueger AM: Contribution of human tumor xenografts to anticancer drug development. Cancer Res 2006, 66:3351-3354.

9. Daniel V, Marchionni L, Hierman JS, Rhodes JT, Devereux WL, Rudin CM, Yung $R$, Parminiani G, Dorsch $M$, Peacock CD, Watlins DN: A primary xenograft model of small-cell lung cancer reveals irreversible changes in gene expression imposed by culture in vitro. Cancer Res 2009, 69(8):3364-3373.

10. Frees KK, Tuveson DA: Maximizing mouse cancer models. Nat Rev Cancer 2007, 7:645-658

11. Voskoglou-Nomilos T, Pater JL, Seymous L: Clinical predictive value of the in vitro cell line, human xenograft and mouse allograft preclinical cancer models. Clin Cancer Res 2003, 9:4227-4239.

12. Hammer S, Sommer A, Fichtner I, Becker M, Rolff J, Merk J, Klar U, Hoffmann J: Comparative profiling of the novel Epothilone, sagopilone, in xenografts derived from primary Non-small cell lung cancer. Clin Cancer Res 2010, 16:1452-1465.
13. Jin $K$, Teng L, Shen $Y$, Ke K, Xu Z, Li G: Patient-derived huan tumor tissue xenografts in immunodeficient mice: a systematic review. Clin Trans Onol 2010, 12:473-480.

14. Merk J, Rolff J, Becker M, Leschber G, Fichtner I: Patient-derived xenografts of non-small-cell lung cancer: a pre-clinical model to evaluate adjuvant chemotherapy? Eur J Cardiothorac Surg 2009, 36:454-459.

15. Tentler JJ, Bradshaw-Pierce EL, Serkova NJ, Hasebroock KM, Pitts TM, Diamond JR, Fletcher GC, Bray MR, Eckhardt SG: Assessment of the In vivo antitumor effects of ENMD-2076, a novel multitargeted kinase inhibitor, against primary and cell line-derived human colorectal cancer xenograft models. Clin Cancer Res 2010, 16(11):2989-2998.

16. Hylander BL, Pitoniak R, Penetrante RB, Gibbs JF, Oktay D, Cheng J, Repasky EA: The anti-tumor effect of Apo2L/TRAIL on patient pancreatic adenocarcinomas grown as xenografts in SCID mice. J Translational Med 2005, 3:22.

17. Cutz J-C, Guan J, Bayani J, Yoshimoto M, Xue H, Sutcliffe M, English J, Flint J, LeRiche J, Yee J, Squire JA, Gout PW, Lam S, Wang YZ: Establishment in severe combined immunodeficiency mice of subrenal capsule xenografts and transplantable tumor lines from a variety of primary human lung cancers: potential models for studying tumor progression-related changes. Clin Cancer Res 2006, 12:4043-4054.

18. Milne NA, Sitarz R, Carvalho R, Polak MM, Ligtenberg M, Pauwels $P$, Offerhaus GJ, Weterman M: Molecular Analysis of primary gastric cancer, corresponding xenografts and two novel gastric carcinoma cell lines reveals novel alterations in gastric carcinogenesis. Human Pathol 2007, 19:141-154.

19. Crescenzi M, Persano L, Esposito G, et al: Vandetanib improves anti-tumor effects of L19mTNFa in xenograft models of esophageal cancer. Clin Cancer Res 2011, 17:447-458.

20. Huynh H, Soo KC, Pierce KH, Chow PK, et al: Xenografts of human hepatocellular carcinoma: a useful model for testing drugs. Clin Cancer Res 2006, 12:4306-4314.

21. Tentler JJ, Tan AC, Weekers CD, Jimeno A, Leong S, Pitts TM, Arcaroli JJ, Messersmith WA, Eckhardt SG: Patient-derived tumor xenografts as models for oncology drug development. Nat Rev Clin Oncol 2012, 9:338-350.

22. John $T$, Kohler D, Pintilie M, et al: The ability to form primary tumor xenografts is predictive of increased risk of disease recurrence in early-stage Non -small cell lung cancer. Clin Cancer Res 2011, 17:134-141.

23. Weiss J, Sos ML, Seidel D, et al: Frequent and focal FGFR1 amplification associates with therapeutically tractable FGFR1 dependency in squamous cell lung cancer. Sci Transl Med 2010, 2(62):62ra93.

24. Zhang J, Zhang L, Su X, Li M, Xie L, Malchers F, Fan S, Yin X, Xu Y, Liu K, Dong Z, Zhu G, Qian Z, Tang L, Zhan P, Ji Q, Kilgour E, Smith PD, Brooks AN, Thomas RK, Gavine PR: Translating the therapeutic potential of AZD4547 in FGFR1amplified non-small cell lung cancer through the use of patient-derived tumor xenograft models. Clin Cancer Res 2012, 18(24):6658-6667.

25. Li D, Ambrogio L, Shimamura T, Kubo S, Takahashi M, Chirieac LR, Padera RF, Shapiro Gl, Baum A, Himmelsbach F, Rettig WJ, Meyerson M, Solca F, Greulich H, Wong K-K: BIBW2992, an irreversible EGFR/HER2 inhibitor highly effective in preclinical lung cancer models. Oncogene 2008, 27:4702-4711.

26. Park B, Jeong BC, Lee KS: Development and characterization of a bladder cancer xenograft model using patient-derived tumor tissue. Cancer Sci 2013, 104(5):631-638.

27. Chaudary N, Pintilie M, Schwock J, Dhani N, Clarke B, Milosevic M, Fyles A, Hill RP: Characterization of the tumo-microenvironment in patient-derived cervix xenografts (OCICX). Cancers 2012, 4:821-845.

28. Dutt A, Ramos AH, Hammerman PS, Mermel C, Cho J, Sharifnia T, Chande A, Tanaka KE, Stransky N, Greulich H, Gray NS, Meyerson M: Inhibitor-sensitive FGFR1 amplification in human Non-small cell lung cancer. PLoS One 2011, 6:e20351.

29. Takafumi K, Hiromasa Y, William WL, LIse V, Junichi S, Michael P, Masaru J, Hiroki O, Tetsuya F, Mamoru O, Nagio T, Katsuyuki K, Kenji S, Hiroshi D, John DM, Marileila V-G, Wan LL, Adi FG, Shinichi T: MET gene amplification or EGFR mutation activate MET in lung cancers untreated with EGFR tyrosine kinase inhibitors. Int J Cancer. 2009, 124(8):1778-1784.

30. Dulak AM, Gubish CT, Stabile LP, Henry C, Siegfried JM: HGF-independent potentiating of EGFR action by c-Met. Oncogene 2011:1-11.

31. Judde JG, Rebucci M, Vogt N, Cremoux P, Livartowski A, Chapelier A, TranPerennou C, Boye K, Defrance R, Poupon MF, Bras-Goncalves RA: Gefitinib and chemotherapy combination studies in five novel human non small cell lung cancer xenografts. Evidence linking EGFR signaling to gefitinib antitumor response. Int J Cancer 2007, 120:1579-1590. 
32. Katzel JA, Fanucchi MP, Li Z: Recent advances of novel targeted therapy in non-small cell lung cancer. J Hematol Oncol 2009, 2:2.

33. Paez JG, Janne PA, Lee JC, Tracy S, Greulich H, Gabriel S, Herman P, Kaye FJ, Lindeman N, Boggon TJ, Naoki K, Sasaki H, Fujii Y, Eck MJ, Sellers WR,

Johnson BE, Meyerson M: EGFR mutations in lung cancer: correlation with clinical response to gefitinib therapy. Science 2004, 304:1497.

34. Lynch TJ, Bell DW, Sordella R, Gurubhagavatula S, Okimoto RA, Briannigan BW, Harris PL, Haserlat SM, Supko JG, Haluska FG, Louis DN, Christiani DC, Settleman J, Haber DA: Activating mutations in the epidermal growth factor receptor underlying responsiveness of non-small-cell lung cancer to gefitinib. N England J Med 2004, 350:2129-2139.

35. Fukuoka M, Wu YL, Thongprasert S, Sunpaweravong P, Leong SS, Sruiranpong V, Chao TY, Nakagawa K, Chu DT, Duffield EL SN, Rulazenkov Y, Speake G, Jiang H, Armour AA, To KF, Yang JC, Mok TS: Biomarker analyses and final overall survival results from a phase III, randomized, open-label, first-line study of gefitinib versus carboplatin/paclitaxel in clinically selected patients with advanced non-small-cell ling cancer in Asia (IPASS). J Clin Oncol 2011, 29(21): 2866-2874.

36. Mitsudomi T, Morita S, Yatabe Y, Negoro S, Okamoto I, Tsurutani J, Seto T, Satouchi M, Tada H, Hirashima T, Asami K, Katakami N, Takada M, Yoshioka H, Shibata K, Kudoh S, Shimizu E, Saito H, Toyooka S, Nakagawa K, Fukuoka M: Gefitinib versus cisplatin plus decetaxel in patients with non-smal-cell lung cancer harbouring mutations of the epidermal growth factor receptor (WJOG3405): an open label, randomized phase 3 trial. Lancet Oncol 2010, 11:121-128.

doi:10.1186/1479-5876-11-168

Cite this article as: Zhang et al:: Establishment of patient-derived nonsmall cell lung cancer xenograft models with genetic aberrations within EGFR, KRAS and FGFR1: useful tools for preclinical studies of targeted therapies. Journal of Translational Medicine 2013 11:168.

\section{Submit your next manuscript to BioMed Central and take full advantage of:}

- Convenient online submission

- Thorough peer review

- No space constraints or color figure charges

- Immediate publication on acceptance

- Inclusion in PubMed, CAS, Scopus and Google Scholar

- Research which is freely available for redistribution 